способствующих всестороннему развитию детей и молодежи, активному их вовлечению в социальную и общественную жизнь, воспитанию гражданской позиции и ответственности перед обществом.

С подростками должна организовываться системная работа с участием органов власти, правоохранительных органов, социальных служб, системы наркологических и психоневрологических диспансеров, учителей.

Но в первую очередь такая работа должна проводиться в семье. Детям и подросткам необходимо прививать человеческие ценности, которые всегда составляли основу воспитания молодого поколения в нашей стране. Это уважение к старшим, забота о младших, помощь слабым. Надо воспитывать в подрастающем поколении патриотизм, любовь и уважение к героической истории нашей Родины и своему народу, прививать потребность в труде, искореняя потребительское состояние, укреплять связь народов России. При этом блокировать все попытки проникновения в их сознание чуждой нам идеологии, при которой они уже не будут считать себя великим народом, народом-победителем и народом-созидателем, а нашу страну великой страной.

1. Алексей Зубец: «Въезд в Россию трудовых мигрантов надо не упрощать, а усложнять», https://migranews.ru/

2. Мигранян А.А., Ткаченко М.Ф. Миграционная политика России и стран-доноров в условиях разноскоростной евразийской интеграции. Санкт-Петербург, АЛЕТЕЙЯ, 2019 год.

3. Бородин С.С., Громыко С.С., Лойт Х.Х. Миграционная политика России и зарубежных стран. ГУАП. Санкт-Петербург, 2011 год.

4. Варшавская Е., Денисенко М. Россияне, не готовые работать / Демоскоп Weekly. 2015. №663-664. http:// www.demoscope.ru/weekly/2015/0663/tema01.php

5. https://paperpaper.ru/school-shooting-russia/

6. https://www.ya-roditel.ru/parents/base/experts/skulshuting-i-kolumbayn-po-russki/

7. https://www.miloserdie.ru/article/rossijskie-kolumbajnery-otkuda-oni-poyavilis-i-kak-im-pomoch/

8. https://rb.ru/story/isis-uses-social-media/

\title{
Хлопов О.А. \\ Подходы к пониманию экологической безопасности в изучении международных отношений
}

ФБГОУ ВО «Российский государственньй гуманитарный университет» (Россия, Москва)

doi: 10.18411/lj-05-2021-327

\section{Аннотация}

В статье обсуждаются экологические проблемы, которые бросает вызов доминирующим структурам и практикам международных отношений, Признание антропоцена новой геологической эрой бросает вызов базовому пониманию значения безопасности. Автором раскрываются zсодержание дискурсов об экологической безопасности, обосновываются актуальность изучения проблем экологической безопасности в рамках изучения международных отношений, подчеркивается вывод о том, что доминирующие концепции и практики в рамках международных исследований ограничивают представление о том, как международное сообщество может и должно реагировать на решения глобальных экологических проблем.

Ключевые слова: экологическая безопасность, антропоцен, изменения климата, международное отношение, экологические угрозы

\section{Abstract}

The article discusses environmental issues that challenge the dominant structures and practices of international relations. The recognition of the anthropocene as a new geological 
era challenges basic understanding of the importance of security. The author reveals discourses on environmental safety, substantiates the relevance of studying environmental safety problems in the framework of the study of international relations, emphasizes the conclusion that the dominant concepts and practices in international studies limit the limits the understanding of how the international community can and should respond to solutions of the global environmental problems.

Key words: environmental safety, enthropocene, climate change, international relations, environmental threats.

Эпоха антропоцена, неофициальный интервал геологического времени, составляющий третье всемирное деление четвертичного периода (2,6 миллиона лет назад по настоящее время), характеризуемый как время, когда коллективная деятельность людей (Homo sapiens) начала существенно изменять земную жизнь, поверхность, атмосфера, океаны и системы круговорота питательных веществ. Группа ученых утверждает, что эпоха антропоцена должна следовать за эпохой голоцена (11700 лет назад до настоящего времени) и началась 1950 г. Термин «антропоцен» происходит от греческого языка и означает «недавний век человека».

Хотя американский биолог Юджин Штёрмер придумал этот термин в конце 1980-х, голландскому химику и лауреату Нобелевской премии Полу Крутцену в значительной степени приписывают привлечение общественного внимания к нему на конференции в 2000 г., а также в информационном бюллетене, выпущенном в том же году. В 2008 году британский геолог Ян Заласевич и его коллеги выдвинули первое предложение принять эпоху антропоцена как формальный геологический интервал. В 2016 г. рабочая группа по антропоцену Международного союза геологических наук $(\mathrm{MCГH})$ проголосовала за рекомендацию антропоцена в качестве официальной геологической эпохи на 35-м Международном геологическом конгрессе. Ученые рекомендовали использовать 1950 год в качестве отправной точки интервала, на том основании, что к этому моменту в истории Земли изотопы плутония, вызванные выпадением осадков при испытаниях ядерного оружия, будут достаточно сконцентрированы, чтобы служить наблюдаемым сигналом в пластах горных пород. Чтобы этот интервал стал официальным, он сначала должен быть принят МСГН и Международной комиссией по стратиграфии.

В настоящее время люди имеют огромное влияние на поверхность Земли, атмосферу, океаны и биогеохимический круговорот питательных веществ. К 2005 г. обрабатываемые земли составляли одну десятую поверхности земли, тогда как примерно три десятых использовались под пастбища. К тому времени еще одна десятая площади суши Земли была отдана под городские районы. По некоторым оценкам, с 1990-х гг. люди ежегодно собирают или контролируют от одной четверти до одной трети биомассы, производимой наземными растениями мира (чистая первичная продукция). Такой широкий контроль над производством растений на Земле в значительной степени объясняется разработкой метода промышленной фиксации азота, называемого процессом Габера-Боша, который был создан в начале 1900-х гг. для использования в искусственных удобрениях и боеприпасах. Индустриализация этого процесса увеличила количество пригодного для использования азота в мире на $150 \%$, что значительно повысило урожайность сельскохозяйственных культур и, наряду с другими технологическими достижениями, способствовало экспоненциальному увеличению численности населения мира с 1,6 до 1,7 млрд. человек в 1900 г. до 7,4 млрд. к 2016 г.

По мере роста населения, потребление энергии увеличивалось, а производство энергии из древесины и легко добываемых ископаемых видов топлива (то есть нефти, природного газа и угля) расширялось. Углекислый газ (СО2), выделяемый в результате пожаров для приготовления пищи и других источников в доиндустриальные времена, 
был меньше, чем количество, выбрасываемое промышленными печами, котлами, угольными электростанциями, транспортными средствами. В 1950-х гг. ученыеклиматологи начали отслеживать ежегодное увеличение средней глобальной концентрации углекислого газа в атмосфере. Многие климатологи утверждают, что накопление $\mathrm{CO} 2$ в атмосфере способствовало глобальному повышению средней приземной температуры на $0,74^{\circ} \mathrm{C}$ в период с 1906 по 2005 гг., потере морского льда в Северном Ледовитом океане и разрушению шельфовых ледников вдоль побережья. Антарктический полуостров, уменьшение размеров горных ледников, изменение преобладающих погодных условий и более частое возникновение экстремальных погодных явлений в различных частях мира.

Безусловно, наиболее значимые свидетельства антропоцена в пластах горных пород будут вызваны резким увеличением числа вымираний, происходящих в этот период. Некоторые экологи отметили, что скорость исчезновения видов, происходящая с середины XX века, более чем в 1000 раз превышала скорость доиндустриального периода, что сравнимо с темпами других массовых исчезновений, происходящих на протяжении истории Земли. Быстрые темпы исчезновения обусловлены продолжающимся преобразованием лесов и других природных территорий в сельское хозяйство и городские земли и ускоренным изменением климата в результате изменений углеродного цикла. В результате ожидается, что в окаменелостях, обнаруженных в слоях горных пород по всему миру в доиндустриальные времена и в последующие, будут существенные различия.

Экологические проблемы остаются в стороне в рамках изучения международных отношений [1]. Тем не менее «экологическая слепота» в исследованиях по международным отношениям не вызывает удивления, т.к. сама природа глобального экологического кризиса, с которым столкнулось международное сообщество, ставят под сомнение традиционные структуры дисциплины и основные теории, которые были созданы в мире и для мира, очень отличного от того, в котором сейчас живет человечество.

Традиционные подходы к изучению международных отношений имеют основные ограничения: 1) государственно-центризм не позволяет построить необходимую планетарную картину реальности; 2) позитивистские и рационалистические парадигмы, чьи предположения о стабильном и предсказуемом мире мешают политикам распознавать нелинейность и неопределенность процессов, а также отсутствие междисциплинарных исследований, что не позволяет охватить сложная сущность планетарного экологического кризиса; 3) дихотомия между природой и обществом игнорирует неразрывную связь между природным и социальным мирами и острую необходимость в трансформации нынешней парадигмы развития.

Антропоцен в некотором смысле "изменил правила игры" в том, как мы можем и должны рассматривать международные отношения. Это предполагает пересмотр некоторые из основных предположений о том, как устроен мир. В контексте антропоцена это означает, что окружающая среда больше не является фоном для геополитики, а скорее является динамической силой, влияющей на глобальную политику.

Антропоцен означает ориентацию на защиту экосистем, в частности их функциональности, перед лицом текущих изменений. Этот фокус представляет собой наилучшее средство продвижения прав и потребностей наиболее уязвимых перед лицом динамичных и продолжающихся экологических изменений: маргинализированных и обедневших групп населения; другие живые существа; и будущие поколения.

В процессе обоснования этой аргументации основное внимание в статье уделяется проблеме изменения климата: возможно, окончательной иллюстрации 
наступления эпохи антропоцена и степени воздействия человечества на функциональность земных систем. Автором указывается на идею различных дискурсов климатической безопасности, отмечая, что эти дискурсы поощряют и отдают приоритет с точки зрения природы климатической угрозы и соответствующих ответных мер на нее, очерчены контуры дискурса об экологической безопасности с акцентом на устойчивость экосистем, а также права и потребности наиболее уязвимых слоев населения.

В конечном итоге наступление антропоцена, и связанный с ним экологический кризис, предполагает необходимость радикальных изменений в нашем понимании и подходе к безопасности. При изучении масштабов экологического кризиса, особенно изменения климата, мы видим растущее понимание идеи, что мы можем подойти к этим вопросам через призму безопасности. Такой подход очевиден в обсуждениях в Совете Безопасности ООН [2].Тем не менее, хотя растет консенсус в отношении того, что мы можем рассматривать такие вопросы, как изменение климата, как проблему безопасности, ведутся споры о том, что мы должны сделать.

Представление об экологических изменений как угрозы безопасности предполагает, что государства и их вооруженные силы должны играть ключевую роль в решении этих проблем, что, в свою очередь, создает риск милитаризации таких проблем, как изменение климата [3]. Возникают вопросы: действительно ли мы хотим, чтобы военные взяли на себя основную ответственность, например, за реагирование на климатический кризис, или если мы определим экологическую проблему как проблему безопасности, ведет ли это к тому, что она будет решаться с помощью срочных, преимущественно нелиберальных мер [4].

В основе общественного договора лежит идея о том, что государство обеспечивает защиту индивидов в опасной и анархической среде. Поэтому неудивительно, что государства постоянно подчеркивают, что их самая важная ответственность или обязанность - обеспечивать безопасность своих граждан. И хотя эта взаимосвязь между безопасностью и политической легитимностью наиболее очевидна в контексте государств, первая статья Устава ООН также определяет главную ответственность ООН как поддержание международного мира и безопасности.

Если безопасность понимается и рассматривается с точки зрения национального государства и его сохранения, то это имеет совсем другие последствия для решения такой проблемы, как изменение климата, чем если бы безопасность понималась с точки зрения международной стабильности, или устойчивости экосистемы. Чтобы изучить предположения и последствия различных представлений о взаимосвязи между изменением климата и безопасностью следует подходить к этой взаимосвязи через призму различных и конкурирующих дискурсов о безопасности.

Дискурсы об \экологической безопасности. Следует различать разные дискурсы о безопасности: структуры значений с разными концепциями, безопасность которых имеет значение; от каких угроз; какими средствами он должен быть защищен или продвинут и какими агентами [5].

Повестка дня угроз в каждом из них выглядит по-разному и основана на разных наборах предположений и обязательств. Но что еще более важно, признание того, что существуют разные дискурсы, имеет решающее значение, потому что они в конечном итоге поощряют разные наборы ответов на экологические вызовы.

Доминирующим дискурсом о безопасности в отношении изменения климата является национальная безопасность. Изменение климата, становится проблемой безопасности в той мере, в какой она угрожает суверенитету или территориальной целостности государства. В конечном счете, для государств, территории которых напрямую угрожает повышение уровня моря, угроза изменения климата является косвенной - это проблема, повышает вероятность конфликта, нестабильности или крупномасштабного перемещения населения. В борьбе с этой угрозой государство 
должно полагаться на собственные силы, а ответные меры в значительной степени адаптивны. Другими словами, вместо того, чтобы принимать совместные меры по предотвращению изменения климата или минимизировать его опасность, государства будут стремиться оградить себя от этих последствий.

Как показывает пример реакции национальной безопасности на «климатических беженцев», мы можем видеть, как жертвы изменения климата представляются как угроза безопасности национального государства [6].

В 2003 г. Пентагон США заказал отчет о последствиях резких климатических сценариев для национальной безопасности. В отчете утверждается, что ряд государств, которые с меньшей вероятностью будут затронуты последствиями изменения климата, могут попытаться принять более строгие меры пограничного контроля для предотвращения перемещения лиц, в результате проявлений изменения климата (например, повышения уровня моря или стихийные бедствия) [7]. В этом случае национальная безопасность перед лицом изменения климата, по-видимому, может быть достигнута путем физического предотвращения того, чтобы наиболее пострадавшие от него проникли в государство.

Приверженность бывшего президента США Д. Трампа к более жестким мерам пограничного контроля (в виде стены на границе с Мексикой) предполагает, что такие барьеры могут возникать не только по причине экологических и климатических катастроф. По некоторым данным, мы уже видим климатические барьеры на границе Бангладеш и Индии, при этом индийские власти стремятся предотвратить приток граждан Бангладеш, перемещенных из-за повышения уровня моря.

В таких странах, как Австралия, где лица, ищущие убежища, прибывающие на лодках, уже рассматриваются как угроза безопасности и содержатся в центрах содержания под стражей в течение длительных периодов времени. Ряд соседних тихоокеанских островных сообществ находятся на переднем крае вынужденного переселения, вызванного климатом.

Этот дискурс в значительной степени совпадает с реалистическим подходом к международным отношениям, для которого характерен скептицизм в отношении эффективного многостороннего сотрудничества.

Как уже давно отмечали теоретики, работающие в рамках традиции критических исследований безопасности, такой подход к мировой политике дает нам немного ресурсов для эффективного решения действительно глобальных или транснациональных проблем безопасности [8].

Очевидным исправлением этого дискурса является дискурс о международной безопасности, в котором признается транснациональный - даже глобальный характер угрозы, исходящей от изменения климата. Здесь изменение климата рассматривается как потенциальная угроза региональной и международной нестабильности, создавая условия, в которых более вероятны крупномасштабные перемещения населения, хрупкость или коллапс правительства и, в конечном итоге, конфликт.

В этом контексте международные организации связывают конфликт в Дарфуре и Сирии с изменением климата (например, ЮНЕП 2007), в то время как Совет Безопасности ООН обсуждал международные последствия изменения климата для безопасности в 2007, 2011, 2018, 2019 и 2020 гг. [2].

Хотя эта повестка дня угроз (нестабильность и конфликт) имеет некоторое сходство с дискурсом национальной безопасности, в конечном итоге основное внимание уделяется тому, как эта динамика становится угрозой нормам и правилам международного сообщества, независимо от того, определяется ли оно порядком или справедливостью.

При этом расширяется спектр средств и средств, хотя адаптация по-прежнему играет роль в реагировании на последствия изменения климата, этот дискурс предполагает роль превентивного ответа для смягчения последствий на изменение 
климата. Это очевидно в попытках применить принцип «Ответственность за защиту» к изменению климата через «Ответственность за подготовку» - обязательство, разработанное Центром по климату и безопасности в США. «Ответственность за подготовку» в значительной степени сосредоточена на «защите климата» существующих сообществ [9] . В этом дискурсе также играют роль не только государства, но и субъекты, обеспечивающие безопасность, включая международные организации.

Но эта концептуализация или подход все же имеет свои ограничения. Вопервых, угроза по-прежнему в значительной степени косвенная, т.к. изменение климата не является угрозой само по себе, оно часто представляется проблематичной, если вызывает нестабильность или уязвимость. И хотя изменение климата признается как проблема общая для всех государств, здесь имеется ограниченное признание конкретной угрозы, представляемой уязвимыми группам населения и, в частности, будущим поколениям. Наконец, если это проблема, ведет к крупномасштабным нарушениям, тогда существует опасность того, что повседневное насилие, связанное с изменением климата (которое наносит значительный ущерб, но не смещает лидеров и не вызывает конфликта), не будет идентифицировано как проблема через призму международной безопасности.

Попытку идентифицировать прямую угрозу изменения климата и отреагировать на нее можно найти в дискурсе безопасности человека. Здесь изменение климата представлено как непосредственная и часто существующая угроза для уязвимых групп населения с точки зрения их жизни и жизненных перспектив средств к существованию.

Теоретики, указывающие на последствия изменения климата для безопасности человека, подчеркивают императивность действий по смягчению последствий, которые нельзя эффективно изолировать от последствий изменения климата [10]. В этом процессе предлагается роль широкого круга участников не только в сокращении выбросов, но и в устранении структурных сил и неравенства, которые определяют уязвимость, в первую очередь, бедность и маргинализация части населения.

Это явно представляет собой более прогрессивный подход к угрозе климатической безопасности. Тот, кто определит само изменение климата, а не просто его последствия как проблему, вероятно, поддержит решительные меры по смягчению последствий для решения проблемы.

Это подход, который находит все большую политическую поддержку, о чем свидетельствуют отчеты Программы развития ООН [11]. Однако даже здесь есть ограничения, особенно в том, что касается степени, в которой этот подход в достаточной мере учитывает особую уязвимость нынешнего и будущих поколений. Для других будущих поколений их острая уязвимость является результатом не только подверженности проблемам изменения климата и ограниченной способности реагировать. Это также результат неспособности напрямую влиять на современные решения и действия, которые будут иметь серьезные последствия для их жизненных перспектив. На этом фундаментальном уровне дискурс о безопасности человека все еще рискует поддержать разделение человека и природы.

Таки образом, в приведенных выше определениях безопасности в контексте изменения климата, национальная, международная или человеческая безопасность, есть ограничения.

Экологическая безопасность. Признавая ограниченность этих дискурсов о безопасности в контексте изменения климата и экологических проблем, следует привести аргументы в пользу экологической безопасности. Экологическую безопасность можно определить как заботу об устойчивости самих экосистем, особенно перед лицом экологических изменений. Однако то, что составляет экосистему и что означает устойчивость, является предметом научных споров. Под экосистемой понимается комплекс организмов, их окружающая среда и их интерактивные 
отношения. Он состоит из трех элементов: 1) люди в данной области, которые взаимодействуют друг с другом; 2) неживые части физической среды (от атмосферы до земли и воды), которые окружают людей; а также; 3) отношения между ними.

Эти экосистемы не имеют определенного размера и пересекаются: они могут быть размером с пустыню или маленькими, как пруд. Между тем, устойчивость экосистемы означает способность экосистем продолжать функционировать перед лицом возмущений или изменений [12].

Сложность функций экосистемы также создает проблемы: например, когда дело доходит до изменения климата, мы не можем точно сказать, будут ли, как и когда различные экосистемы безвозвратно нарушены, например, из-за изменения температуры или количества осадков. В конце концов, мы должны - как предполагает принцип предосторожности - ошибиться в сторону осторожности.

Таким образом, отсутствие точности или конкретности явно затрудняет понимание того, что составляет экологическую безопасность. Тем не менее что составляет «международное сообщество» или «человечество» в контексте международной безопасности или безопасности человека, ненамного яснее. На национальном, международном уровне или уровне безопасности человека, мы сталкиваемся с четкими проблемами в отношении того, что представляет собой угроза, и как на нее реагировать.

В конечном итоге экологическую безопасность лучше рассматривать как ориентацию или чувствительность, а не как окончательное или объективное условие. Всегда будут споры о том, угрожает ли функциональность экосистемы или ставится ли под угрозу изменение климата, и насколько серьезно и в какой форме.

Таким образом, задача состоит в том в том, чтобы побудить исследователей или лиц, определяющих политику, ориентироваться на рассмотрение проблемы изменение климата, через призму устойчивости экосистемы как способ поощрения прогрессивных и эффективных ответных мер на основе международного сотрудничества [13].

По сути, акцент на экосистемах перед лицом экологических изменений позволяет нам уделять приоритетное внимание правам и потребностям наиболее уязвимых сообществ, которые непосредственно подвержены проявлениям изменения климата в развивающихся странах, но также и будущим поколениям. Как уже отмечалось, уязвимость здесь определяется как результат воздействия, адаптивная способность и способность вносить вклад в существующие процессы принятия решений и. Исходя из этого, будущие поколения особенно уязвимы к последствиям изменения климата, и акцент на устойчивость экосистемы рассматривается здесь как лучшее средство решения этой проблемы. В дискурсе об экологической безопасности центральная угроза, исходит от изменения климата. Это, в свою очередь, требует прямого ответа на него, который решает проблему причин изменению климата.

В конечном счете, это предполагает центральную роль смягчения последствий: действия, направленные на значительное сокращение выбросов парниковых газов. Даже потенциально спорные проекты, такие как геоинженерия посредством удаления углекислого газа или управления солнечным излучением, также могут рассматриваться как средство обеспечения экологической безопасности [14]. Это особенно актуально с учетом того, что глобальные выбросы продолжают расти и изменения климата теперь неизбежно. Но эти подходы к управлению последствиями изменения климата или посредством технологического вмешательства должны оставаться вторичными по отношению к решению проблемы об их источнике.

Конечно, все вышесказанное вызывает вопросы о том, кто обеспечивает безопасность, учитывая, что экосистемы не имеют определенной идентичности или формы, и те, кто больше всего подвержен воздействию экологической незащищенности, почти по определению имеют наименьшие возможности или ресурсы для устранения причин этой незащищенности. Ответственность за устранение 
последствий изменения климата для безопасности экосистем определяется двумя терминами: способность сознательно вносить вклад в причинение вреда климату и способность сознательно участвовать в практических действиях, направленных на решение самой проблемы [15]. Таким образом, степень ответственности определяется, в конечном счете, тем насколько конкретный субъект вносит свой вклад в проблему изменения климата и насколько он способен ее решать эти экологические проблемы.

Очевидно, что уровень ответственности распространяется от индивидуального выбора и действий до роли частных компаний, особенно компаний, занимающихся добычей ископаемого топлива, международных организаций и государств[16]. Все они несут, в той или иной степени, ответственность за устранение угрозы, создаваемой изменением климата.

На пути к экологической безопасности существуют серьезные препятствия. Среди прочего, мы могли бы указать на институциональную основу государственной системы, которая препятствует действиям, ориентированным на решение глобальных проблем; пределы существующих этических рамок, которые побуждают нас сосредоточиться на обязательствах перед согражданами или даже членами нашей собственной семьи; способы экономического обмена, обычно добыча и эксплуатация ради краткосрочной выгоды; культурные обычаи (употребление в пищу красного мяса или вождение больших автомобилей), или проблемы, связанные с подлинным знанием потребностей или интересов наиболее уязвимых точек, в которых функциональность экосистемы [17].

Критические теоретики называют их «имманентными» возможностями: возможностями для прогресса, существующими в рамках определенного порядка . Например, принцип предосторожности - часть «Декларации Рио» на Саммите Земли 1992 г. (ЮНСЕД) - поддерживает идею о том, что «отсутствие полной научной уверенности не должно использоваться в качестве причины для откладывания экономически эффективных мер по предотвращению деградации окружающей среды.

Концепция «общей, но дифференцированной ответственности», также одобренная на ЮНСЕД в рамках Рамочной конвенции ООН об изменении климата, признает универсальное обязательство действовать, но указывает на то, что государства имеют разные обязательства, которые следует рассчитывать «на основе справедливости, и в соответствии с их общими, но дифференцированными обязанностями и соответствующими возможностями». Эти разные нормы, принципы и концепции подтверждают ключевые элементы дискурса об экологической безопасности: императив действовать перед лицом неопределенности; идея ответственности, основанная на возможностях; и императив выйти за рамки разделения между природой и человечеством.

Ряд НПО и групп гражданского общества активно поддерживают принципы экологической безопасности, включая недавнее движение «Восстание за вымирание». Между тем на переговорах по самому последнему климатическому соглашению в Париже в 2015 г. признание особой уязвимости и обязательств перед сообществами развивающихся стран, находящихся на переднем крае изменения климата, было заметно в стремлении ограничить потепление до $1,5^{\circ} \mathrm{C}$. и в признании «утраты и ущерба».

Из целого ряда движений и организаций, которые поддерживают принципы, согласующиеся с экологической безопасностью, движение «Extinction Rebellion» - это движение, сделавшее это, возможно, наиболее явно и прямо. Появившись в Великобритании в 2018 г., его члены изначально призвали к признанию «экологической чрезвычайной ситуации», безотлагательно принять меры по «прекращению утраты биоразнообразия» и изложили видение изменений, сфокусированных на «создании мира, пригодного для будущих поколений» [18]. С тех 
пор это движение быстро превратилось в международное, с крупными протестами не только в Великобритании в 2018 и 2019 гг., но и в США, Германии, Австралии, Бельгии, Нидерландах, Испании и Швейцарии.

Очевидное наступление эпохи антропоцена явно поднимает серьезные и сложные вопросы о природе взаимоотношений человечества с миром природы. Обеспечения безопасности является центральным вопросом для политической легитимности ключевых игроков в международной системе, в первую очередь государств. Обоснование актуальности экологической безопасности в рамках изучения международных отношений представляется одним из средств решения этих проблем, и доминирующие концепции и практикам международных отношений ограничивают пределы того, как мы можем и должны реагировать на подлинный экзистенциальный глобальный экологический кризис.

По поводу понятия «безопасности» ведутся серьезные споры, но политику безопасности следует рассматривать как зависящую от того, как понимается сама безопасность. Реализация и продвижение экологической безопасности на практике является сложной задачей по целому ряду причин, но мы можем определить принципы и практики, связанные с этим подходом в современном контексте решения экологических проблем.

1. Green J. F., Hale T. N. Reversing the Marginalization of Global Environmental Politics in International Relations: An Opportunity for the Discipline. PS: \ Political Science \& Politics, 2017, № 50(2), pp. 473479.

2. Maertens L. Climatizing the UN Security Council. International Politics. 2021.

3. Marzec R. P. Militarizing the Environment: Climate Change and the Security State. Minneapolis: University of Minnesota Press. 2015.

4. Neocleous M. .Critique of Security. Edinburgh: Edinburgh University Press. 2008.

5. McDonald M. Climate Change and Security: Towards an Ecological Security Discourse? \International Theory, 2018 № 10(2), pp. 153-80.

6. Baldwin A., Methmann, C., Rothe D. Securitizing "Climate Refugees": The Futurology of ClimateInduced Migration \ Critical Studies on Security. 2014№ 14(2), pp. 121-30.

7. Schwartz P., Randall D. An Abrupt Climate Change Scenario and Its Implications for United States National Security. 2003. URL: http://www.edf.org/documents/3566_AbruptClimateChange.pdf (дата обращения 15.04.2021).

8. Booth K. Theory of World Security. Cambridge: Cambridge University Press. 2007.

9. Werrell, C., Femia, F. The Responsibility to Prepare and Prevent, October. Center for Climate and Security, Washington DC. 2019. URL: https://climateandsecurity.org/wp-content/uploads/2019/10/theresponsibility-to-prepare-and-prevent_a-climate-security-governance-framework-for-the-21stcentury_2019_10.pdf. (дата обращения 18.04.2021).

10. Matthew R., Barnett J., McDonald B., O’Brien, K. (es) .Global Environmental Change and Human Security. Cambridge, Mass: MIT Press.2010.

11. UNDP. . Fighting Climate Change: Human Solidarity in a Divided World. New York: Palgrave. 2007.

12. Adger N. Vulnerability \ Global Environmental Change. 2006, №16, pp.: 268-81.

13. Хлопов О.А. Глобальные проблемы экологической безопасности и изменения климата в контексте международного сотрудничества // Тенденции развития науки и образования». 2019. № 53.(2) С 68-74

14. Symons J. Ecomodernism: Technology, Politics and the Climate Crisis. Cambridge: Polity. 2019.

15. Алинов, M. Экологическая безопасность: уроки глобального кризиса: монография. Германия: LAP LAMBERT Acad. Publ., 2018. 208 c.

16. Пенджиев А. М. Изменение климата и возможности уменьшения антропогенных нагрузок : возобновляемая энергетика, климат, экология, механизм чистого развития, международное сотрудничество : монография. Германия : LAP LAMBERT Acad. Publ., 2012. 168 c.

17. Gardiner S. M. A Perfect Moral Storm: The Ethical Tragedy of Climate Change. New York: Oxford University Press. 2011.

18. Extinction Rebellion. This Is Not a Drill. London: Penguin. 2019.

19. BBC. 2019. What Is Extinction Rebellion and What Does It Want? BBC News, 7 October. Available at: https://www.bbc.com/news/uk-48607989 (дата обращения 20.04.2021). 